\title{
Lattice Misfit between Inclusion and Acicular Ferrite in Weld Metal of Low Carbon Low Alloy Steel*
}

\author{
by Tomonori Yamada**, Hidenori Terasaki*** and Yu-ichi Komizo***
}

\begin{abstract}
To clarify the mechanism of acicular ferrite formation in low carbon submerged arc weld metals of a Ti-B system with different aluminum contents, the lattice misfit between inclusion and acicular ferrite was investigated. The inclusions were directly sliced into thin foils by a focused ion beam device and crystallographic analyses were performed using a transmission electron microscope. These inclusions were surrounded by a narrow Ti-enriched layer which was identified as TiO. Our results showed that the Baker-Nutting orientation relationship was satisfied between the narrow $\mathrm{TiO}$ on the inclusion surface and acicular ferrite.
\end{abstract}

Key Words: Weld metal, Acicular ferrite, Inclusion, Nucleation, Lattice misfit

\section{Introduction}

Acicular ferrite is regarded as the most desirable microstructural feature, in view of strength and toughness, in high strength steel weld metals. Therefore, the behavior of the nucleation and growth of acicular ferrite has been extensively studied $^{1-7)}$ and the weld metal of refined acicular ferrite is practically used in industry. However, the mechanisms of the acicular ferrite nucleation have been not completely clarified yet.

It is known that inclusions in weld metal strongly contribute to the nucleation of acicular ferrite ${ }^{3,4)}$. The previous research result revealed that the inclusions which actually acted as acicular ferrite nucleation sites were multi-phase structure. It consists of amorphous phase of a Si-Mn system, $\mathrm{MnS}$ and galaxite spinel $\mathrm{MnAl}_{2} \mathrm{O}_{4}$. The lattice misfit between inclusions and acicular ferrite were calculated, but it is not a considerably effective site. However, these inclusions related to acicular ferrite formation were surrounded by a narrow titanium oxide ${ }^{7}$.

In the present work, the narrow titanium oxide forming on inclusion surface was investigated from the crystallographic points of view. The lattice misfit between the narrow titanium oxide and acicular ferrite was investigated.

\section{Experimental procedure}

The tested materials were low carbon Ti-B submerged arc weld metals with an oxygen content of about $450 \mathrm{ppm}$. The welding speed and heat input were $0.0217 \mathrm{~m} \mathrm{~s}^{-1}$ and $5.16 \times 10^{6} \mathrm{Jm}^{-1}$.

${ }^{*}$ Received: 2008.11 .18

** Student Member, Graduate school of Engineering, Osaka University

${ }^{* * *}$ Member, Joining and Welding Research Institute, Osaka University
Table 1 shows the chemical compositions of weld metals used. The compositions of inclusions were varied by changing aluminum content while the contents of the other elements kept constant. The $\mathrm{Al} / \mathrm{O}$ ratios (mass ratio) were $0.48,0.73$ and 1.52 . It was confirmed that the microstructure of $\mathrm{Y} 1(\mathrm{Al} / \mathrm{O}=0.48)$ and $\mathrm{Y} 2$ $(\mathrm{Al} / \mathrm{O}=0.73)$ consists mainly of acicular ferrite nucleated from inclusions within austenitic grain at elevated temperature and that the microstructure of $\mathrm{Y} 3(\mathrm{Al} / \mathrm{O}=1.52)$ consists mostly of bainite with ferrite laths formed from austenite grain boundaries during cooling ${ }^{8)}$. Figure1 shows microstructures of the each samples in room temperature by optical microscope.

To clarify the evolution mechanism, the inclusions were investigated from the crystallographic points of view. The foiled samples including inclusions were prepared with a focused ion beam (FIB) device and were observed with a transmission electron microscope (TEM) which was operated at an acceleration voltage of $200 \mathrm{kV}$. The element analysis of the inclusions was made by energy disperse x-ray spectroscopy (EDS).

Table 1 Chemical compositions of weld metals used (mass\%)

\begin{tabular}{|c|c|c|c|c|c|c|c|c|}
\hline & $\mathrm{C}$ & $\mathrm{Si}$ & $\mathrm{Mn}$ & $\mathrm{Al}$ & $\mathrm{Ti}$ & $\mathrm{B}$ & $\mathrm{O}$ & $\mathrm{N}$ \\
\hline Y1 & 0.090 & 0.35 & 1.72 & 0.022 & 0.014 & 0.0035 & 0.046 & 0.0042 \\
\hline Y2 & 0.085 & 0.37 & 1.75 & 0.035 & 0.015 & 0.0040 & 0.048 & 0.0041 \\
\hline Y3 & 0.086 & 0.39 & 1.81 & 0.073 & 0.013 & 0.0040 & 0.048 & 0.0035 \\
\hline
\end{tabular}

\section{Result and discussion}

Figure 2a shows bright field image of inclusion from Y1 in which acicular ferrite was observed. This inclusion mainly consisted of an amorphous phase and partly consisted of $\mathrm{MnAl}_{2} \mathrm{O}_{4}$. Figure $2 \mathrm{~b}$ shows EDS mapping analysis of titanium. The titanium detected on the surface of inclusion. Figures $2 \mathrm{c}$ and $2 \mathrm{~d}$ show an EDS spectrum from the interface between inclusion 


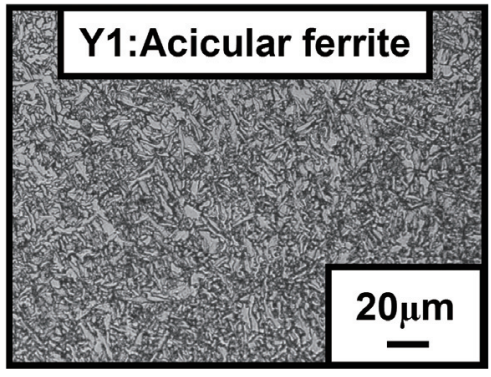

a) Microstructure of Y1

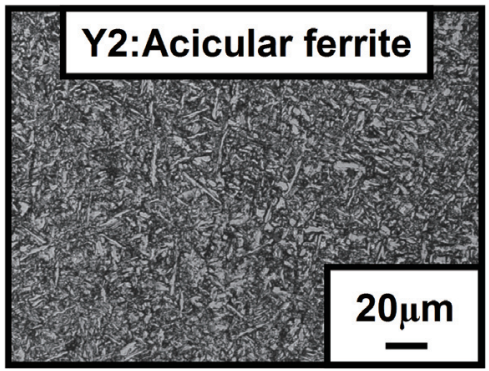

b) Microstructure of $\mathrm{Y} 2$

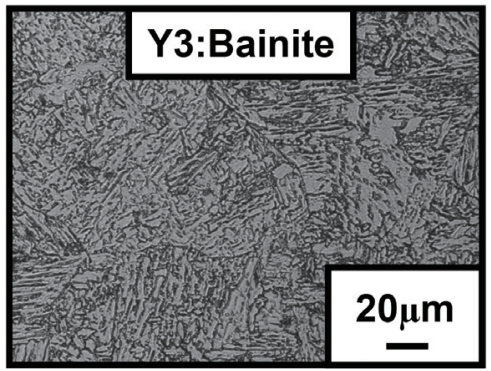

c) Microstructure of $\mathrm{Y} 3$

Fig. 1 Optical microstructures of the samples by optical microscope

and ferrite. The $\mathrm{Cu}$ peaks was caused lay the $\mathrm{Cu}$ mesh to support the thin foil. The Fe peak is from the matrix and $\mathrm{Al}, \mathrm{Si}$ and $\mathrm{Mn}$ peaks are from the inclusion. It thought that the $\mathrm{C}$ peak is contamination. Therefore, the $\mathrm{O}$ and Ti peaks are from inclusion and its surface.

Figure 3a shows a bright field image of inclusion from Y2 in which acicular ferrite was observed. This inclusion consisted of amorphous phase and $\mathrm{MnAl}_{2} \mathrm{O}_{4}$. However, the area of amorphous zones was narrow compared to that in the inclusion in Y1. Figure $3 \mathrm{~b}$ shows EDS mapping analysis of titanium. The titanium was detected on the inclusion surface, similar to those observed in Y1. Figures $3 \mathrm{c}$ and $3 \mathrm{~d}$ show EDS spectra from the interface between inclusion and ferrite. The $\mathrm{O}$ and $\mathrm{Ti}$ peaks were detected from inclusion surface, similar to those observed in Fig.2.

As shown in Figs. 2 and 3, inclusions contributing to acicular ferrite nucleation were multi-phase particles consisting of $\mathrm{MnS}$,
$\mathrm{MnAl}_{2} \mathrm{O}_{4}$ and amorphous phases. As reported in the previous study ${ }^{9}$, the $\mathrm{MnAl}_{2} \mathrm{O}_{4}$ inclusion with a lattice misfit no less than $8.6 \%$ and the $\mathrm{MnS}$ inclusion with a lattice misfit no less than $7.6 \%$ can not be considered to act as an effective nucleation site.

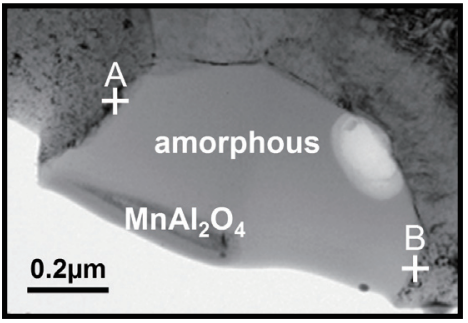

a) Bright field image

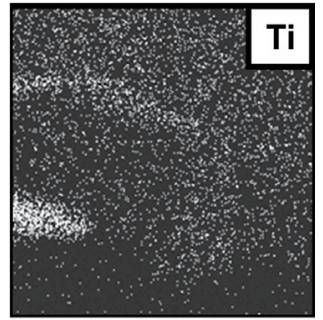

b) EDS mapping analysis

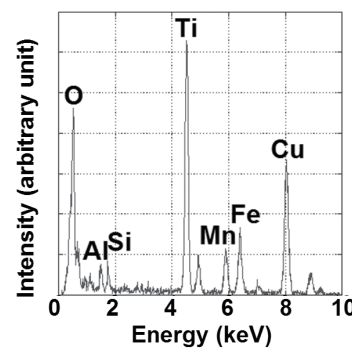

c) EDS analysis (location A)

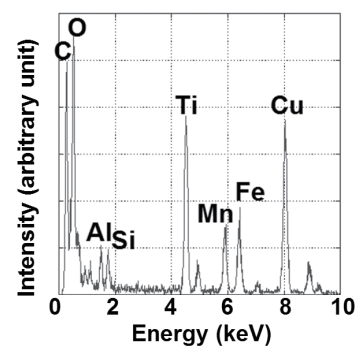

d) EDS analysis (location B)
Fig. 2 TEM analysis of inclusion in Y1

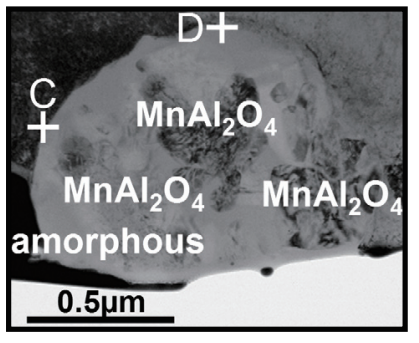

a) Bright field image

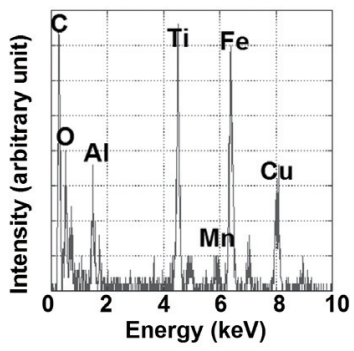

c) EDS analysis (location C)

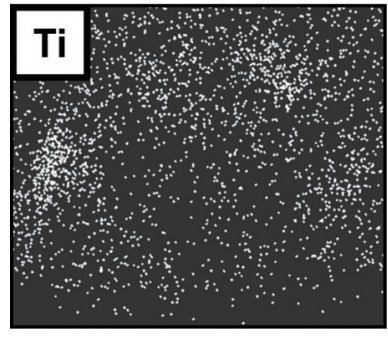

b) EDS mapping analysis

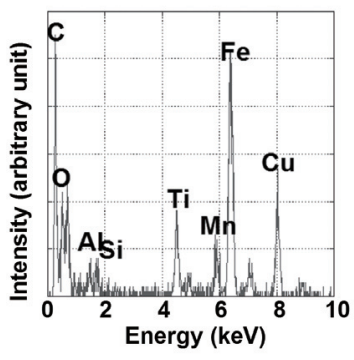

d) EDS analysis (location D)
Fig. 3 TEM analysis of inclusion in Y2 

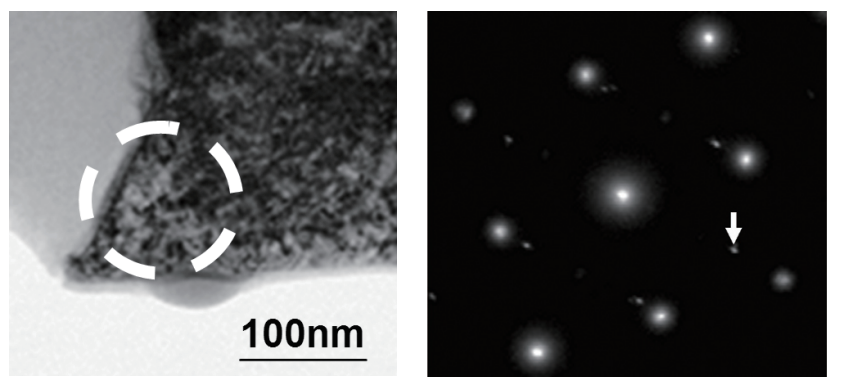

a) Bright field image
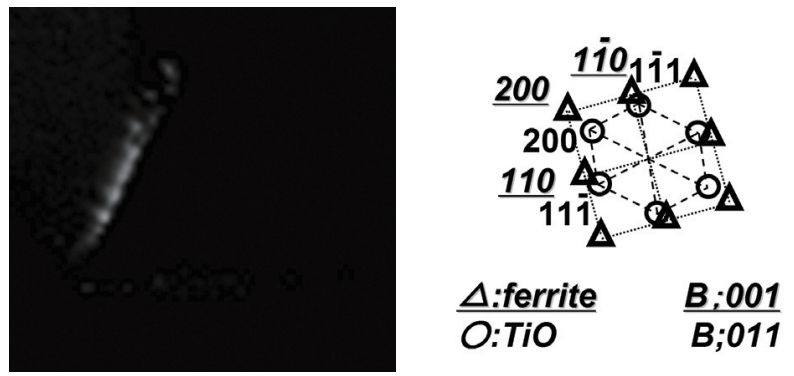

c) Dark field image

b) Selected area diffraction pattern

Fig. 4 TEM analysis of inclusion in Y1
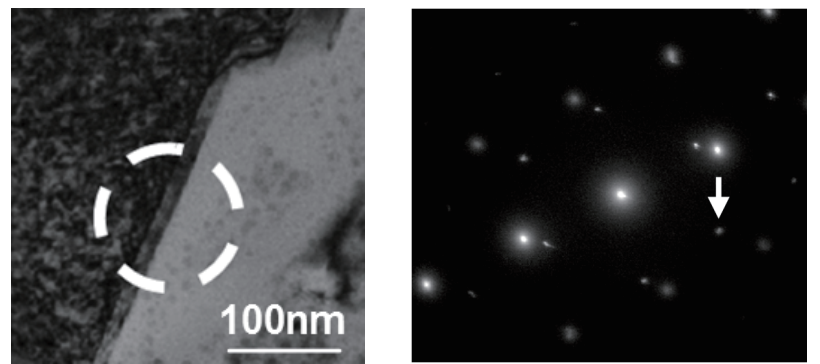

a) Bright field image
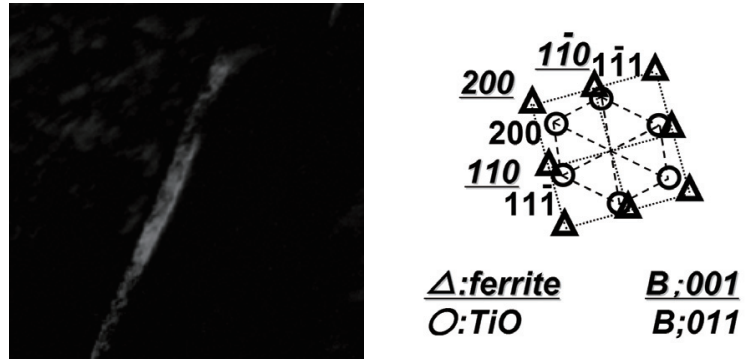

c) Dark field image

b) Selected area diffraction pattern

Fig. 5 TEM analysis of inclusion in Y2

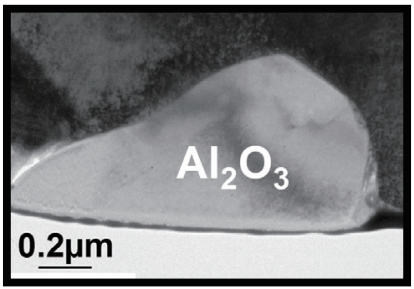

a) Bright field image

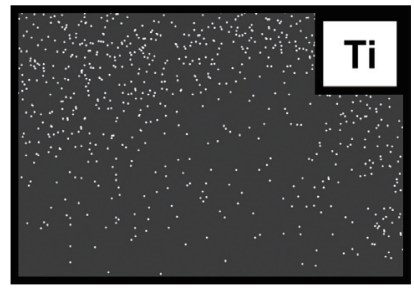

b) EDS mapping analysis
Fig. 6 TEM analysis of Inclusion in Y3

Then, the authors consider that this local titanium-enriched layer (Ti-O system) promotes acicular ferrite nucleation.

Figure $4 \mathrm{a}$ shows the bright field image of the observed inclusion in Y1. Figure $4 \mathrm{~b}$ shows the corresponding selected area diffraction pattern from the interface between inclusion and ferrite. These diffraction patterns can be indexed as these of TiO and ferrite, as shown in Fig.4b. Figure $4 \mathrm{c}$ shows a dark field image, taken using spot of the (200) diffraction of TiO. The TiO existed in the surface of inclusion and its thickness was estimated to be $10-20 \mathrm{~nm}$ range.

Figure 5a shows the bright field image of the observed inclusion in Y2. Figure 5b shows the corresponding selected area diffraction pattern from the interface between inclusion and ferrite. This crystal structure resulted in $\mathrm{TiO}$ and ferrite, same as Y1. The TiO thickness was about $20 \mathrm{~nm}$, as shown in Fig. 5c which shows a dark field image, taken using spot of the (200) diffraction of TiO.

The lattice matching theory ${ }^{10)}$ is accented as a basic idea to explain the role of inclusions in heterogeneous nucleation. In the theory, following crystal orientation relationship is demanded in order to minimize semi-coherent strain energy.

$$
\begin{aligned}
& \mathrm{TiO}\{100\} / / \alpha-\mathrm{Fe}\{100\} \\
& \mathrm{TiO}<011>/ / \alpha-\mathrm{Fe}<001>
\end{aligned}
$$

These relations were almost satisfied, as shown in Fig.4 and Fig.5. These results suggest that they have Baker-Nutting (B-N) orientation relationship ${ }^{11,12)}$. In this case, lattice misfit was $3.0 \%$. Therefore, this result shows that orientation relationship between $\mathrm{TiO}$ and acicular ferrite satisfies lattice matching theory.

In the weld with $\mathrm{Al} / \mathrm{O}$ ratio of 1.52 in which only bainite was formed, inclusions consisted of single phase $\mathrm{Al}_{2} \mathrm{O}_{3}$ and no $\mathrm{Ti}$ enriched layer existed, as show in Fig.6.

It can be considered that the nano-scale $\mathrm{TiO}$ layer on the inclusion surface promotes acicular ferrite nucleation supplying low interface energy. 


\section{Conclusions}

Transmission electron microscopy (TEM) observations were made to investigate the crystallographic relationship between inclusions and acicular ferrite in low carbon Ti-B weld metals with three levels of $\mathrm{Al} / \mathrm{O}$ ratio. The findings obtained in the present research are as follows.

(1)The inclusions which related to acicular ferrite formation were surrounded by a narrow titanium oxide ( $\mathrm{TiO})$ layer.

(2)The Baker-Nutting orientation relationship was satisfied between the $\mathrm{TiO}$ layer and acicular ferrite.

(3)The thickness of $\mathrm{TiO}$ layer was $10-20 \mathrm{~nm}$.

(4)The lattice misfit between $\mathrm{TiO}$ and nucleated ferrite was 3.0\%.

(5)It can be concluded that the $\mathrm{TiO}$ on the inclusion surface contributes to the heterogeneous nucleation of acicular ferrite, supplying low interface energy.

\section{Acknowledgements}

The authors are grateful to Mr. E. Taguchi, Research Center for Ultra-High Voltage Electron Microscopy, Osaka University, Osaka, Japan, for his help in EDS mapping.

\section{Reference}

1) E.Levine and D.C.Hill: Structure-Property Relationships in Low C Weld Metal, Metall. Trans. A, 8A (1977), 1453-1463.
2) C.L.Choi and D.C.Hill: A Study of Microstructural Progression in As-Deposited Weld Metal, Weld. J., 57 (1978), 232s-236s.

3) N.Mori, H.Homma, S.Okita and M.Wakavayashi: Mechanism of Notch Toughness Improvement in Weld Metals Containing Ti and B, J. Jpn. Weld. Soc., 50 (1981), 174-181.

4) Y.Ito, M.Nakanishi and Y.Komizo: Effect of Oxygen on Transformation of Low Carbon Weld Metal -Study on Microstructure and Toughness of the Weld Metal (1st Report)-, J. Jpn. Weld. Soc., 50 (1981), 1211-1218.

5) G.Thewlis: Transformation kinetics of ferrous weld metals, Mater. Sci. Technol., 10 (1994), 110-125.

6) H.Terasaki and Y.Komizo: Sci. Technol. Weld. Joining, 11 (2006), 561-566.

7) T.Yamada, H.Terasaki and Y.Komizo: Microscopic Observation of Inclusions related to Acicular Ferrite Formation in Steel Weld Metal, Q. J. Jpn. Weld. Soc., 25 (2007), 416-420

8) T.Yamada, H.Terasaki and Y.Komizo: Microstructural Evolution in Low Carbon Steel Ti-B Weld Metals with Several Al Levels, Q. J. Jpn. Weld. Soc., 25 (2007), 514-518.

9) T.Yamada, H.Terasaki and Y.Komizo: Microscopic observation of inclusions contributing to formation of acicular ferrite in steel weld metal, Science and Technology of Welding and Joining, 13 (2008), 118-125.

10) B.L.Bramfitt: The Effect of Carbide and Nitride Additions on the Heterogeneous Nucleation Behavior of Liquid Iron, Metall. Trans. 1 (1970), 1987-1995

11) S.Zhang, H.Hattori, M.Enomoto and T.Tarui: Ferrite Nucleation at Ceramic/Austenite Interfaces, ISIJ INT., 36 (1996), 1301-1309.

12) M.Mizuno, I.Tanaka and H.Adachi: CHEMICAL BONDING AT THE Fe/TiX ( $\mathrm{X}=\mathrm{C}, \mathrm{N}$ OR O) INTERFACES, Acta materi., 46 (1998), 1637-1645. 